\title{
The Future of Coal
}

\section{Dr. Chris Foreman, Purdue University, West Lafayette}

Chris Foreman (Ph.D. Computer Science and Engineering, University of Louisville, 2008) is a Senior Member of IEEE, the Power and Energy Society, and holds both B.S. (1990) and M.Eng. (1996) degrees in Electrical Engineering, also from the University of Louisville. He is an Assistant Professor in the Department of Electrical and Computer Engineering Technology at Purdue University. He teaches and performs research in renewable energy systems, smart power grids, industrial control systems, and cybersecurity. He has over 15 years of power industry experience with companies such as Westinghouse Process Control Division (now Emerson Process Management), Cinergy (now Duke Energy), and Alcoa Inc.

\section{Karina Clarissa Halim, Purdue University}

Karina Halim is a senior undergraduate student majoring in chemical engineering at Purdue University. She is set to graduate on December 2014 with a minor in management. She likes to learn about energy and environment, in terms of future challenges. She has done some energy and environment related research during her college life with faculties in technology department. The most recent research is on coal and nuclear energy with Professor Raji Sundararajan of Electrical and Computer Engineering Technology department.

\section{Dr. Rajeswari Sundararajan, Purdue University, West Lafayette}




\section{The Future of Coal}

Abstract

Coal remains a primary energy source for the production of electricity. It is well established in most industrialized nations and rapidly growing in developing nations. World reserves for coal are abundant, with hundreds of years remaining. However, many problems exist in the areas of environmental, safety, and a retiring or insufficient workforce. These problems, coupled with the lack of renewable energy sources to meet baseload demand for power, will result in the ongoing need for new graduates. Universities have been slow to educate students in coal power generation. A solution to this is presented in this paper in the form of a lesson plan with introductory information of the coal power generation process, equipment utilized, and some of the policies and concerns surrounding coal use. This paper can serve to start a dialog in energy courses and provide future directions for students interested in pursuing energy careers.

\section{Introduction}

Coal for utility-scale electrical power generation has been in widespread use for approximately a century. It is currently the largest energy source for electrical power and remains cheap and abundant. ${ }^{1}$ While many renewable and alternative power generation processes continue to be explored, coal is expected to remain a primary solution for electricity needs for decades to come. Figure 1 illustrates the projected growth of coal consumption by Organisation for Economic Co-operation and Development (OECD) ${ }^{2}$ member nations as well as non-OECD nations. ${ }^{3}$ China and India are among the prime drivers for the increase in coal consumption by non-OECD nations as their large populations and growing standard of living fuel the demand for cheap electricity.
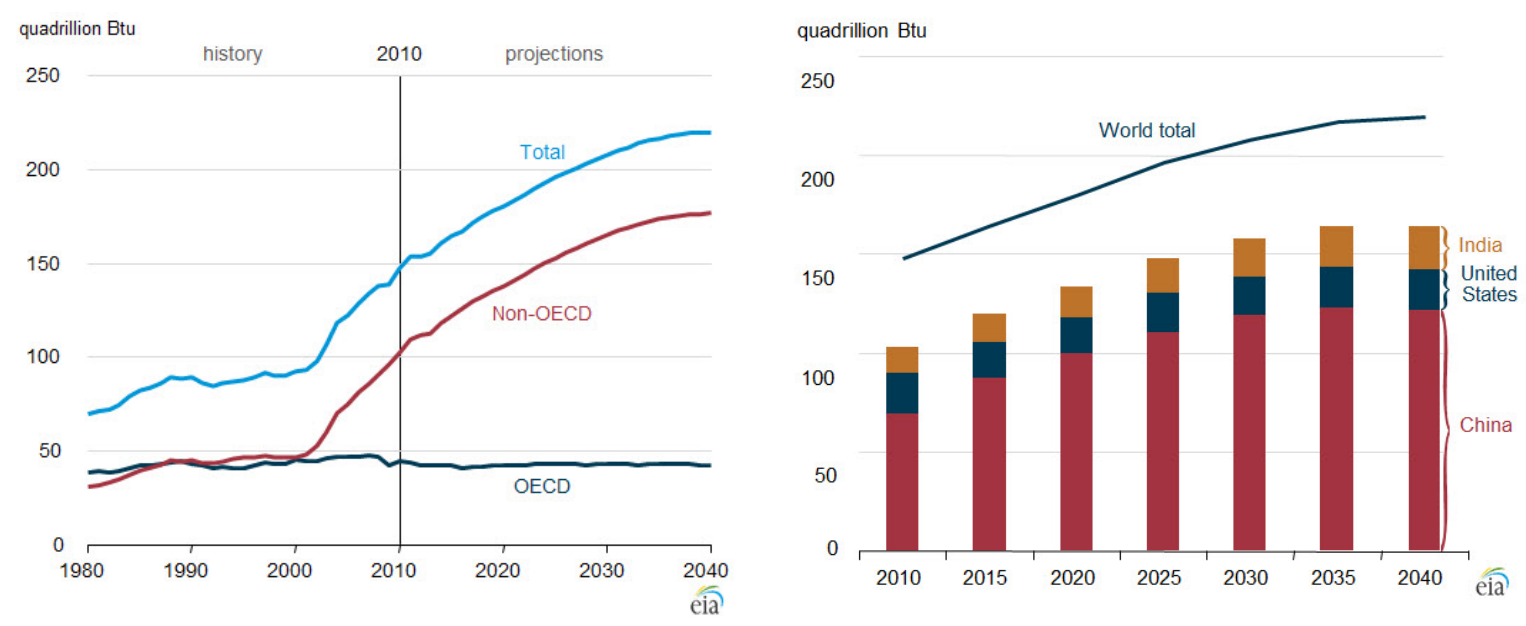

Figure 1 - World coal consumption by region, $1980-2040 .^{3}$ 
The increase in coal power in other nations and an aging workforce in the U.S. coal power industry is also creating a demand for new employees. ${ }^{4}$ These new employees need advanced skills to implement the latest technologies for efficiency improvements and mitigate concerns for the negative environmental impacts of coal use. Therefore, it is important for new graduates in engineering and technology who aspire to work in the field of electrical power generation to understand both existing and new coal technologies. ${ }^{4,5}$ This understanding will facilitate short-term improvements in existing coal power as well as better prepare society for the inevitable long-term replacement of coal.

This paper is intended to provide a foundation for coal power technology to facilitate the preparation of new students in power generation careers. Students that find careers in coal power will be able to directly benefit from this, while students who focus in alternative power careers, for example solar, will gain a sufficient understanding of coal power to perform comparative analyses and engineer alternative forms of power such that they can integrate with, and eventually replace, coal use.

Coal power education

Current educational shortcomings

Although coal is an old and seemingly established form of power generation, there is still a need for new graduates with technical skills applicable to coal power. For the past several years, power education in general has been lacking ${ }^{5}$, and most of the momentum in new power education has been in alternative power generation technologies such as solar and wind. The reputation of coal power has been very negative in terms of environmental, safety, and even economic societal impacts. ${ }^{6}$ Universities do very little to educate in coal power due to this reputation. However, alternative forms of electrical power generation still cannot meet baseload demand for electricity and the principle alternative to coal, nuclear, also suffers from a similar negative reputation. Germany, who has been a large advocate for renewable energy, has already found the need to revert back to some coal power to stabilize supply and demand as they phase out nuclear power. ${ }^{7}$ Despite the unpopularity of coal, the demand for experience in coal power will be present for some time and due to its widespread use, there will be significant benefits to society for new technologies that mitigate those negative impacts.

Suggestions for educational direction

A lesson plan to initiate student interest and provide direction for further study can be initiated through a set of lectures on the following topics. Lectures can be derived from the material following in this paper and the provided sources.

1. Coal resources and world consumption

2. The environmental and safety impacts 
3. Coal plant operational and regulatory issues

4. Existing coal power processes and equipment

5. New coal technologies such as Integrated Gasification and Combined Cycle (IGCC) and supercritical boiler operation

These topics would be typical to introduce undergraduate engineering and technology students to the concepts of coal power within a hosting energy course. Additional topics could be introduced depending on the theme of the hosting course, for example, integrating renewable energy into the power grid, or further examining the economic market for coal power. When introduced to students at the sophomore level, these topics can provide directions for students to pursue in their junior, senior, and graduate years of study, whether in coal power or a competing technology.

Environmental impacts and mitigation technologies

Coal is a high carbon content mineral formed through the compression of organic matter over millions of years. Coal is the byproduct one of the Earth's past processes of carbon uptake. Through combustion, we release this naturally sequestered carbon from millions of years past, and this is the contribution of coal to global warming. In Figure 2, we see how coal as an electricity fuel source compares with other fuels in this respect. Entrained in this mineral are also found mercury, antimony, arsenic, and other heavy metals, as well as nitrogen and sulfur, which all contribute to additional environmental problems.

\section{$\mathrm{CO}_{2}$ Emissions by Fuel}

Evolution from 1971 to 2007 of world* $\mathrm{CO}_{2}$ emissions** by fuel $\left(\mathrm{Mt}\right.$ of $\left.\mathrm{CO}_{2}\right)$

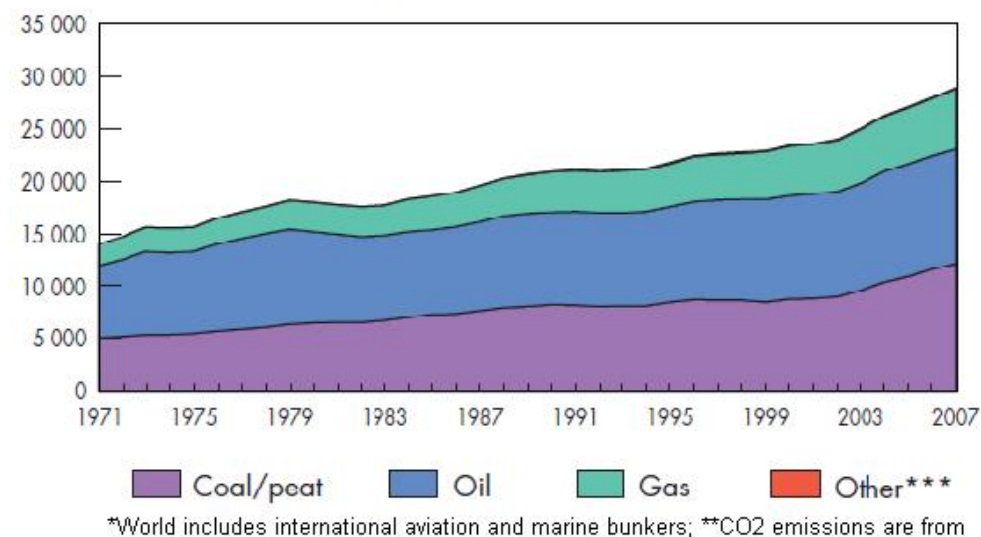

* World includes international aviation and marine bunkers; " $\mathrm{CO} 2$ emissions are from fuel combustion only; Other includes industrial and non-renewable municipal waste

Figure 2 - World $\mathrm{CO} 2$ emissions by fuel in electricity generation. ${ }^{8}$ 
Figure 1 illustrates the consumption of coal by nation. By noting Figure 3, we can also see the nations with the largest reserves. Coal is still abundant in most all of the industrialized nations. In fact, this graph illustrates that the U.S. has more coal energy than the Middle East has oil energy in terms of Billion Tonnes Oil Equivalent (BTOE).

Coal reserves are available in almost every country worldwide
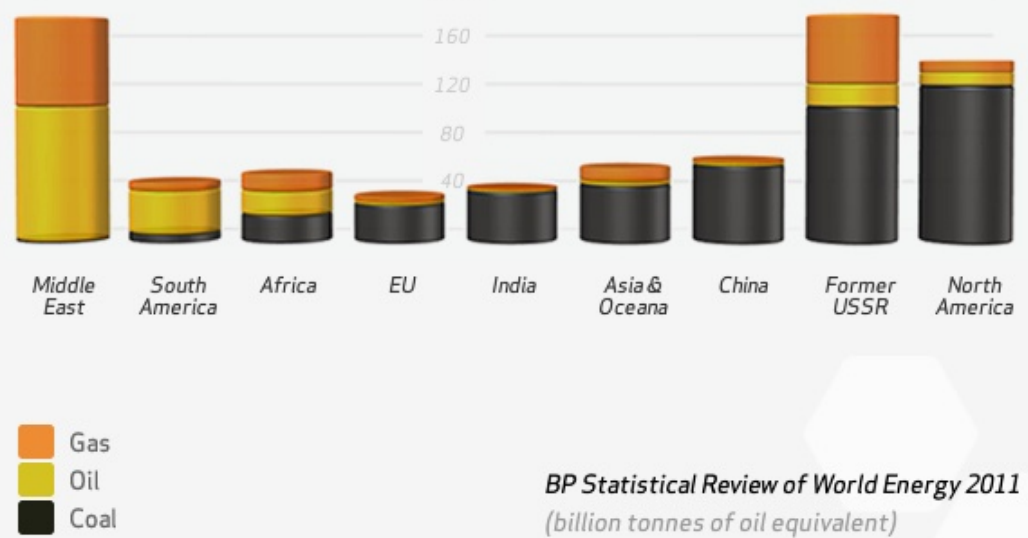

BP Statistical Review of World Energy 2011 (billion tonnes of oil equivalent)

Figure 3 - Location of the world's fossil reserves. ${ }^{9}$

Given the environmental problems associated with coal combustion, as well as its continued cheap abundance, there have been some efforts towards clean coal technologies. Some of these efforts take the form of cleaning up emissions, such as the use of Fluidized Gas Desulfurization (FGD) or scrubbers to remove sulfur dioxide, Selective Catalytic Reduction (SCR) to remove nitrogen oxides, and electrostatic precipitators to remove particulate emissions, to name some of the more commonly used systems. Carbon Capture and Sequestration (CCS) has also been explored to directly address carbon dioxide emissions. Other efforts for alternative coal power processes, such as Integrated Gasification and Combined Cycle (IGCC) and supercritical boilers, seek to generate electrical power from coal in a cleaner and/or more efficient process. These last two technologies will be discussed in the next section.

As expected with all emission mitigating approaches, the implementation of these are very costly, and most result in reduced power generation efficiency. North America and Europe have mandated most of these approaches in new and many existing coal plants. However, developing nations such as India and China often bypass these clean air technologies in favor of building quicker and cheaper solutions for their rapidly growing electricity appetite.

Fluidized Gas Desulfurization (FGD)

Fluidized Gas Desulfurization ${ }^{10}$, also known as scrubbing, is a method of liquid washing the exhaust (flue) gas of a coal plant to remove sulfur dioxide. Typically, a slurry solution of water and pulverized limestone or lime is injected into the flue gas stream. This solution captures 
sulfur dioxide as well as some particulates. Sulfur dioxide is an acidic gas and when combined with rainwater in the atmosphere, results in acid rain. Removal efficiencies are on the order of $97 \%$ and costs can be on the order of US $\$ 100 \mathrm{MM}+$. The fly ash removed from the flue gas can often be used to make synthetic gypsum, which is used in drywall production. This process is illustrated in Figure 4.

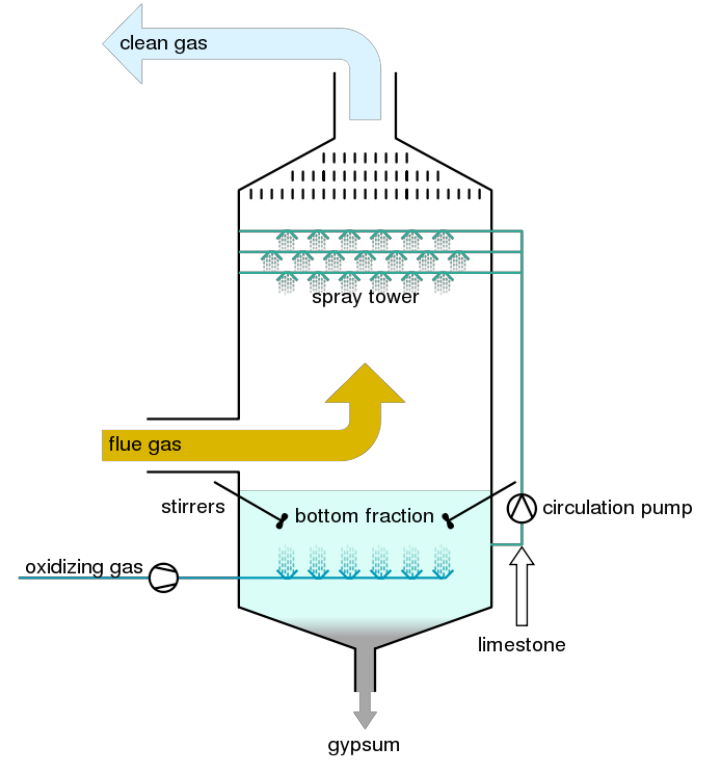

Figure $4-$ Schematic of FGD process. ${ }^{11}$

Since sulfur dioxide is an acidic gas, the alkaline solution of limestone, $\mathrm{CaCO}_{3}$, or lime, $\mathrm{Ca}(\mathrm{OH})_{2}$, and water solution will neutralize this gas while relocating the sulfur atom to the solid fly ash, $\mathrm{CaSO}_{3}$, which collects at the bottom of the FDG reactor. This fly ash can be further oxidized to gypsum, $\mathrm{CaSO}_{4}$, to result in a useful byproduct for drywall production. The reaction equations (1) and (2) are as follows.

$$
\begin{aligned}
& \mathrm{CaCO}_{3} \text { (solid) }+\mathrm{SO}_{2}(\text { gas }) \rightarrow \mathrm{CaSO}_{3}(\text { solid })+\mathrm{CO}_{2}(\text { gas }) \\
& \mathrm{Ca}(\mathrm{OH})_{2}(\text { solid })+\mathrm{SO}_{2}(\text { gas }) \rightarrow \mathrm{CaSO}_{3}(\text { solid })+\mathrm{H}_{2} \mathrm{O} \text { (liquid) }
\end{aligned}
$$

Selective Catalytic Reduction (SCR)

Selective Catalytic Reduction ${ }^{12}$ is a process to remove nitrogen oxides from the exhaust of a coal plant. Nitrogen oxides are a respiratory irritant and also have some damaging effects on the environment. SCR is achieved by the injection of anhydrous ammonia, $\mathrm{NH}_{3}$, into the exhaust (flue) gas of the coal plant to result in elemental nitrogen and water. Various ceramic compounds catalyze the reaction, similar to the catalytic converter used in automobiles. The removal efficiency is typically between $80-90 \%$ and costs can be on the order of US\$100MM + . The reaction equations (3) and (4) are given as follows. 


$$
\begin{aligned}
& 4 \mathrm{NO}+4 \mathrm{NH}_{3}+\mathrm{O}_{2} \rightarrow 4 \mathrm{~N}_{2}+6 \mathrm{H}_{2} \mathrm{O} \\
& 2 \mathrm{NO}_{2}+4 \mathrm{NH}_{3}+\mathrm{O}_{2} \rightarrow 3 \mathrm{~N}_{2}+6 \mathrm{H}_{2} \mathrm{O}
\end{aligned}
$$

An obvious concern for SCR is the use and storage of large amounts of anhydrous ammonia. This is both expensive and dangerous. An alternative process is Selective Noncatalytic Reduction (SNCR), which employs urea instead of anhydrous ammonia. The process is also non-catalytic, which saves on construction costs. Removal efficiencies for this process are only $30-50 \%$.

\section{Electrostatic Precipitators}

Electrostatic precipitators ${ }^{13}$ are more common than FGD or SCR, and have been in use longer, since the 1950s. They are designed to capture particulate matter from the exhaust (flue) gas stream by taking advantage of electrostatic attraction. Removal efficiencies can be as high as $99 \%$, although the use of high resistivity coal, typically found in low sulfur varieties, can reduce this efficiency. The costs for precipitators can also approach US\$100MM. This process is illustrated in Figure 5.

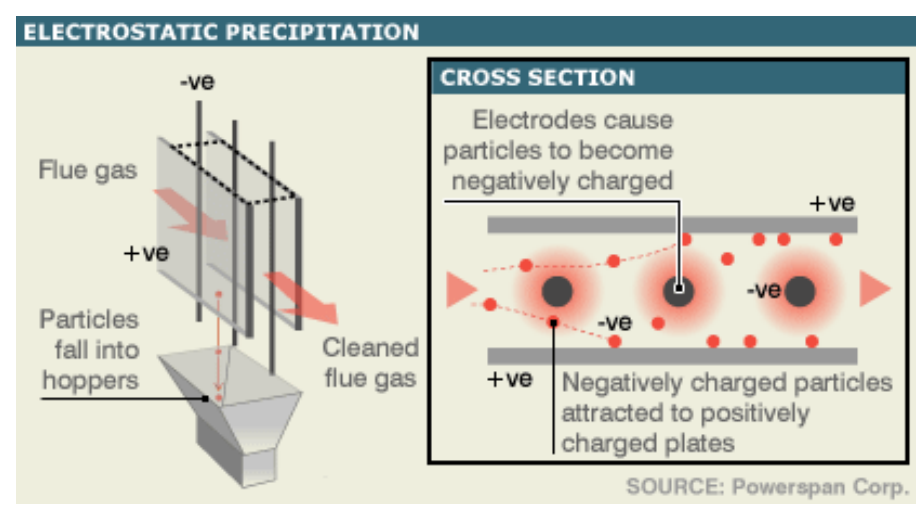

Figure 5 - Electrostatic precipitation process. ${ }^{14}$

As particles entrained in the flue gas stream pass by electrodes charged to a high potential, typically tens of thousands of volts, they acquire a negative electrical charge. Plates surrounding the electrodes have a positive charge. The attraction of opposite charges removes the particles from the flue gas steam and causes them to cling to the plates. When the plates become laden with particulate waste, hammer-like devices called rappers strike the plates causing the particulate waste to fall to a collection bin for removal. 
A note on complications in the U.S. market

A major influence on any energy technology is the regulatory environment in which it operates. Coal power has a history of strong opposition by both the general public as well as the scientific community for its pollution resulting from combustion and the environmental impacts of its mining. This is especially true in recent years, as climate change and a preference for green energy have become popular. Accidents resulting in injury and death due to coal mining and power generation have also gained in attention recently. Contrasted with this is the business model of coal power, especially in the U.S., which has a strong lobby to protect such a cheap source of electricity. This cheap electricity has been largely responsible for the higher standard of living and vigorous manufacturing that built the U.S. and other Western economies. ${ }^{15}$ Third world nations see this and now want their time of growth on the economy of coal.

In the U.S., the Environmental Protection Agency (EPA) is tasked with, among other things, the enforcement of regulations limiting emissions from coal plants. The Clean Air Act ${ }^{16}$ passed in the 1970s was intended to mitigate the negative environmental impacts of coal power. An unfortunate clause in this act was that existing coal plants did not have to meet the new emissions standards and thus, they were grandfathered-in until retirement. At that time, the design life of a coal plant was typically 30 years. Now coal plants remain in operation often past 50 years receiving only maintenance but no technology improvement. This has resulted in dirtier and less efficient plants staying in operation and ultimately negating the intention of the Clean Air Act. In fact, should a power utility attempted to improve a plant's efficiency through improved technology, that plant would then be required to meet these costly regulations by implementing the environmental mitigation technologies discussed in this paper. The combination of the scrubbers, SCRs, and precipitator systems often exceed the cost of the power generation components themselves. In regulated states where coal plants operate as regulated monopolies, the coal fuel costs are passed along to power consumers, so fuel savings do not benefit the company. Thus, there is negative motivation for existing plants to improve.

Coal power technologies

Traditional Coal-Fired, Steam-Turbine (CFST) generation

Despite the vintage of CFST generation technology ${ }^{17}$, it is this technology that provides more electricity than any other energy source. The base technology is also the foundation by which nearly all, new coal power is being constructed. In fact, renewable sources for electricity are compared with coal to measure their economic and environmental benefits, so an understanding of this technology is important. Note that most units of measure in the coal power industry are still in the English System, especially in the U.S. 
The basic process of CFST generation is the pulverization of coal rock into a fine powder using mills. This powder is fed into a boiler furnace and mixed with air such that a combustible atmosphere is achieved. This combustion releases heat, which in turn boils water in the boiler drum to produce steam under pressure. This steam is sent to the turbine that does rotational work through expansion on the shaft of an electrical generator. Rotation of the generator results in AC electrical power, which is then sent to the power grid. This process is illustrated in Figure 6, including the environmental mitigating technologies discussed previously.

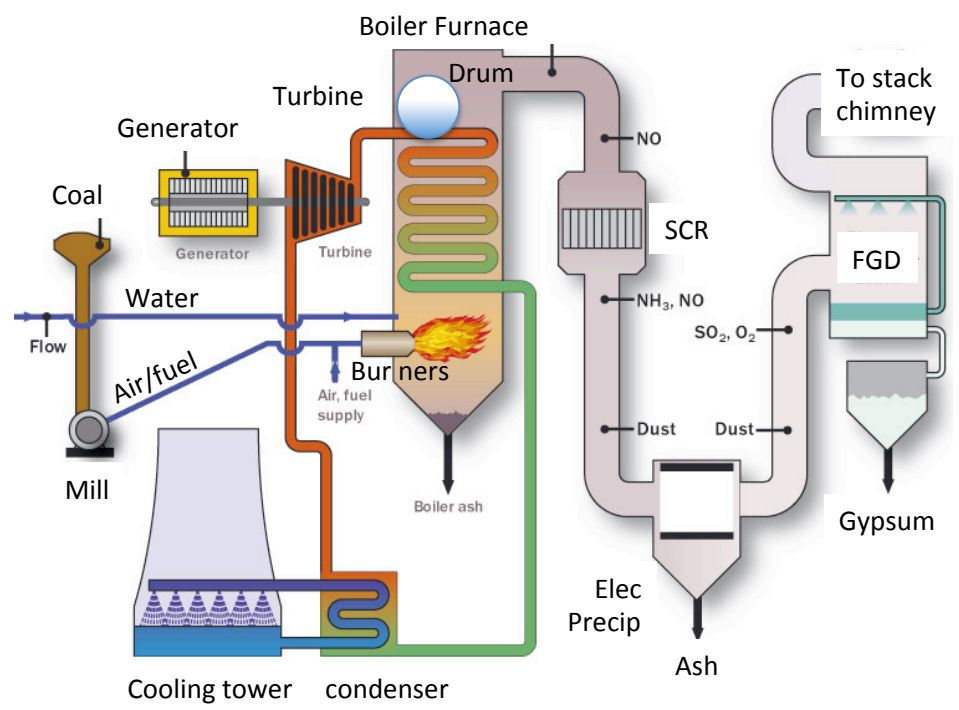

Figure 6 - Coal plant process. ${ }^{18}$

A complete discussion of this process is too lengthy and beyond the scope of this paper. However, this should serve as a starting point for a student's basic understanding. The efficiency of a coal-generating unit is measured by its heat rate, $H R$, given in equation (5). The heat rate is the rate at which coal is converted into electricity, and has the units of BTU/kWhr. A pound of coal has a certain amount of heating value, $H H V$, which varies from 4000-15000 BTU/lb depending on its quality and carbon content. The quantity of coal burned in the unit, Coal, results in a heat energy input, $Q$, given in equation (6). This is divided by the electrical energy generated, which is the work done by the generator, $W$. Lower values of heat rate are better as this indicates less coal necessary (less heat energy input) for a given amount of electrical energy output. Typical values for heat rate vary from the very good of around $9000 \mathrm{BTU} / \mathrm{kWhr}(38 \%$ efficient), to poor of around $11000 \mathrm{BTU} / \mathrm{kWhr}$ (31\% efficient). Both BTU and $\mathrm{kWhr}$ are units of energy. To convert to efficiency, $\eta$, the units are canceled and the resulting number inverted to get electrical energy output divided by heat energy input. This is shown in equation (7).

$$
\begin{gathered}
H R=\frac{Q_{\text {coal }}(\mathrm{BTU})}{W_{\text {elec }}(\mathrm{kWhr})} \\
Q_{\text {coal }}=H H V\left(\frac{\mathrm{BTU}}{\mathrm{lb}}\right) \cdot \operatorname{Coal}(\mathrm{lb})
\end{gathered}
$$




$$
\eta=\frac{W_{\text {elec }}(\mathrm{kWhr})}{Q_{\text {coal }}(\mathrm{BTU})} \frac{3412(\mathrm{BTU})}{(\mathrm{kWhr})}=\frac{1}{H R} \frac{3412(\mathrm{BTU})}{(\mathrm{kWhr})}
$$

Some typical values for other operating parameters are given as follows.

- Steam temperature, higher values are better limited by the metallurgy of the boiler tubes and turbine, typically $1005 \mathrm{degF}$.

- Steam pressure, which varies by electrical output (size), typically 2000-3000 PSI.

- Steam flow, again varying by size, on the order of one to a few MMlb/hr.

- The thermodynamic process is the Rankine cycle.

- Construction costs are typically US\$2,000-4,000/kW.

- Turbine/Generator rotational speed of $3600 \mathrm{rpm}$ for a two-pole rotor at $60 \mathrm{~Hz} \mathrm{AC}$.

Integrated Gasification and Combined Cycle (IGCC)

Integrated Gasification and Combined Cycle ${ }^{19}$ integrates three process stages. The first stage is the gasification of coal into a gaseous fuel. The second stage is to burn this gas in a combustion turbine operating on the Brayton cycle. The third stage sends the exhaust gas from the combustion turbine to a Heat Recovery Steam Generator (HRSG) to drive a steam turbine operating on the Rankine cycle. By integrating these three stages together, higher energy conversion efficiency is achieved by making best use of the total heat in the process. In the gasification stage, the coal fuel can be cleaned more effectively and cheaper than by using FGD, SCR, and electrostatic precipitators. These stages may also be used individually in other applications, such as one or both thermodynamic cycles with natural gas, or the use of gasified coal as a heating fuel without either of these thermodynamic cycles.

The gasification stage combines the carbon in coal, oxygen from the air, and steam from the HRSG to produce a fuel gas, known as syngas, composed of carbon monoxide and hydrogen. Syngas can be easily filtered of particulates and processed to remove sulfur before combustion. Elemental sulfur becomes a valuable byproduct of the process. The primary reaction equation (8) is given as follows.

$$
2 \mathrm{C}(\text { coal })+\mathrm{H}_{2} \mathrm{O}(\text { steam })+\mathrm{O}_{2} \rightarrow \mathrm{CO}+\mathrm{CO}_{2}+\mathrm{H}_{2}
$$

The reaction is endothermic, so it requires heat to proceed. Heat is provided through the partial combustion, or pyrolysis, of the coal itself in a gasifier and/or the heat energy from the combustion turbine exhaust.

The combustion turbine stage burns the syngas to make use of the expansive energy of combustion to drive a turbine, which is connected to the first electrical generator. The exhaust from this stage is sent to a HRSG, which uses the latent heat energy in the exhaust to boil water to produce steam. The steam turbine stage then makes use of the thermal energy in this steam to 
drive a turbine similar to the CFST process discussed previously, which is connected to the second electrical generator.

It is the combining of these two stages that results in a Combined Cycle (CC), where both the expansive and thermal energy of combustion is utilized. The Integration of Gasification (IG) completes the IGCC process. A diagram of the process is illustrated in Figure 7.

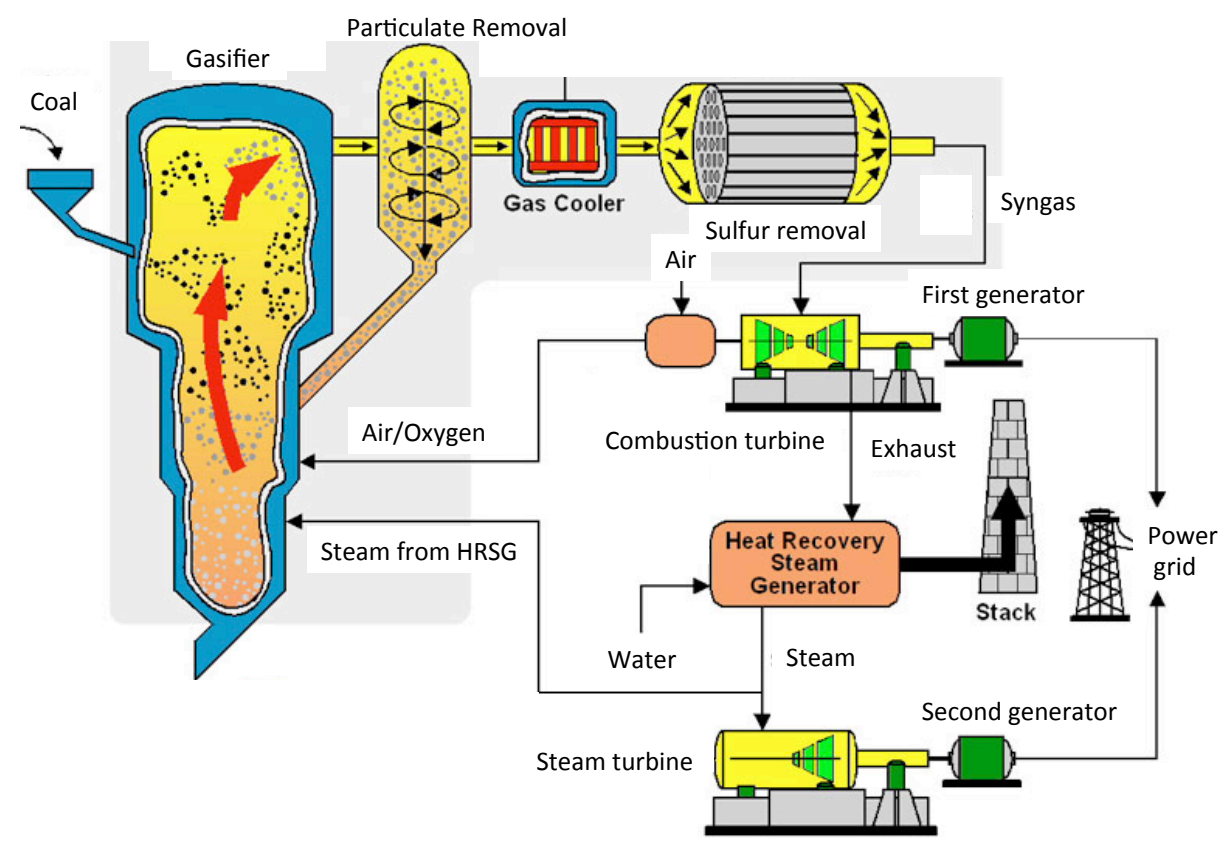

Figure 7 - An IGCC integrated process. ${ }^{20}$

Figure 7 illustrates a simplified process. There are many variations and complications depending on the installation. The typical efficiencies obtained by the IGCC process range from $52-57 \%$ overall for coal energy input divided by total electrical energy output. This can result in approximately $60-70 \%$ of the coal use, and subsequent carbon dioxide production, of a traditional CFST plant. While a traditional CFST is still cheaper to operate, carbon emission limitations and/or increased costs of coal can make IGCC a better alternative.

Supercritical boiler operation

Supercritical boiler operation follows a very similar process to CFST generation in that pulverized coal is combusted in a boiler furnace to drive a steam turbine and generator for electrical energy. The primary difference is that the steam temperature is much higher, and the water does not flash over to steam in a boiler drum as it does in a subcritical CFST process. Instead, water is heated beyond the critical temperature and critical pressure, and then sent to the turbine casing still in liquid form. Upon input to the turbine, the water flashes over to steam. This results in a higher efficiency of $40-45 \%$ due to the higher temperatures and the reduced loss of heat in transfer from the boiler to the turbine. The primary enabling technology for this is 
improved materials in the metallurgy of the boiler tubes and turbine blades. Figure 8 illustrates the supercritical region for water.

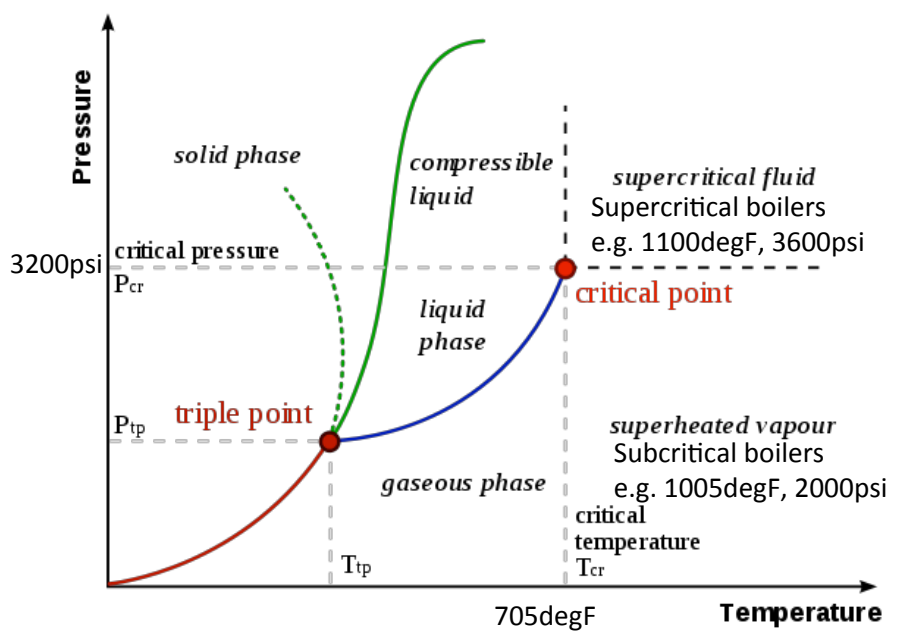

Figure 8 - Supercritical region for water. ${ }^{21}$

Steam temperatures for supercritical operation start at around $1100 \mathrm{degF}$ and higher with the latest designs beyond $1200 \mathrm{degF}$ as metallurgy advances.

Conclusions

This paper has demonstrated the importance of coal power education and its significance to new graduates both to support existing coal power plants as well as explore new coal technologies. Students studying alternative power processes, such as solar and wind, also need a basic understanding of coal power for comparison purposes. Some of the policy and environmental problems have also been discussed, along with mitigating technologies. Finally, the traditional coal power process and some new coal power technologies have been illustrated. All of these can serve as a foundation for discussion in an energy course, recommended at the undergraduate level in engineering or technology, to introduce students to an old technology that still accounts for the largest energy source for electrical power. As universities increase their awareness of the need for education in this area, a starting point such as this will be required.

The operation of coal plants in the U.S. is influenced by both free market and regulatory motivations. Coal power continues as cheap electricity generation drives high profits, while regulatory issues impede improvements and innovation. In the near future, coal will remain a key energy source. Thus, the next generation of graduates will need to address these problems. Eventually, coal plants do retire, and given the difficulty of alternative energy sources to meet baseload demand for power, coupled with the need for cleaner energy, innovation in coal power is a critical problem for the next generation of engineering and technology graduates to address. 
Further reading

Sources of additional information to aid instructors in the development of their own course plans follow. These web addresses were last verified on 3 February 2014.

- http://www.eia.gov, U.S. Energy Information Center

- http://energy.gov/fe/office-fossil-energy, Dept. of Energy Office of Fossil Energy

- http://www.worldcoal.org/, World Coal Association

- http://www.powermag.com/, Power Magazine, including coal power

- http://en.wikipedia.org/wiki/Coal power, Wikipedia coal power starting point

- http://www.nrel.gov/tech_deployment/tools.html, software tools for power and energy analysis

- http://www.ipcc.ch, Intergovernmental Panel on Climate Change

- http://www.epa.gov/, Environmental Protection Agency

References

1. World Coal Association, Coal Matter: Coal and Electricity Generation, www.worldcoal.org, 2013.

2. Organisation for Economic Co-operation and Development, www.oecd.org, 2013.

3. U.S. Energy Information Administration, www.eia.gov, 2013.

4. Michael J. Ashworth, "Preserving knowledge legacies: workforce aging, turnover and human resource issues in the US electric power industry," The International Journal of Human Resource Management, vol. 17, no. 9, pp. 1659-1688, 2006.

5. Heydt, G.T. and Vittal, V., "Feeding our profession [power engineering education]," Power and Energy Magazine, IEEE, vol. 1, no. 1, pp. 38-45, 2003.

6. Jeff Goodell, Big Coal: The Dirty Secret Behind America's Energy Future, First Mariner Books, New York, New York, pp. 97-169, 2007.

7. Peter Friederici, "Why Is Germany's Greenest City Building a Coal-Fired Power Plant?," InsideClimate News, Jul 24, 2013.

8. International Energy Agency, www.iea.org, 2010.

9. BP plc, BP Statistical Review of World Energy, 2011.

10. Biondo, S.J. and Marten, J.C., "A History of Flue Gas Desulphurization Systems Since 1850," Journal of the Air Pollution Control Association, vol. 27, no. 10, pp. 948-961, October 1977.

11. Wikipedia, Wikimedia Commons Creative Commons ShareAlike 1.0 License, user Sponk, found at https://upload.wikimedia.org/wikipedia/commons/d/d0/Flue_gas_desulfurization_unit_EN.svg, Dec 2013.

12. Wikipedia, "Selective catalytic reduction," found at https://en.wikipedia.org/wiki/Selective catalytic reduction, Dec 2013.

13. Wikipedia, "Electrostatic precipitator," found at https://en.wikipedia.org/wiki/Electrostatic precipitators, Dec 2013.

14. Powerspan Corp., found at http://www.learncax.com/blog/2013/11/26/electrostatic-precipitators-espanalysis-using-cfd/, Dec 2013.

15. Clark, G., and Jacks, D., "Coal and the Industrial Revolution," European Review of Economic History, 11(1), pp. 39-72, 2007.

16. U.S. Environmental Protection Agency, "Clean Air Act," found at www.epa.gov/air/caa/, Dec 2013.

17. Wikipedia, "Fossil-fuel power station," found at https://en.wikipedia.org/wiki/Coal_power, Dec 2013.

18. Wikispaces, "How Coal Power Works," found at http://coalpower.wikispaces.com/How+Coal+Power+Works, Dec 2013. 
19. Duke Energy, "How IGCC Works," found at http://www.duke-energy.com/about-us/how-igcc-works.asp, Dec 2013.

20. National Energy Technology Laboratory, "Pinon Pine IGCC Power Project," Project Fact Sheet, Process Flow Diagram, found at http://www.netl.doe.gov/technologies/coalpower/cctc/cctdp/project briefs/pinon/pinondemo.html, Dec 2013.

21. Discover Physiks, found at http://fisikamir.blogspot.com/2012/02/change-of-phase.html, Dec 2013.

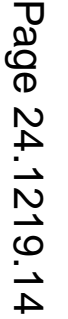

